УДК 621.396.677.73

ОВСЯНИК Ю. А. ${ }^{1}$, ДУБРОВКА Ф. Ф. ${ }^{1}$, ДУБРОВКА Р. ${ }^{\circ}{ }^{2}$

\title{
АНАЛИЗ КОАКСИАЛЬНЫХ РУПОРОВ С ЧАСТИЧНЫМ ДИЭЛЕКТРИЧЕСКИМ ЗАПОЛНЕНИЕМ
}

\author{
${ }^{1}$ Национальный технический университет Украины \\ «Киевский политехнический институт», \\ Украина, Киев, 03056, пр-т Победы 37 \\ ${ }^{2}$ Queen Mary, University of London, \\ Великобритания, Лондон, Mile End Road, E1 4NS
}

\begin{abstract}
Аннотация. Представлены результаты разработки математической модели новой коаксиально-рупорной антенны с частичным диэлектрическим заполнением. Профиль рупора аппроксимирован отрезками коаксиального волновода с трехслойным диэлектрическим заполнением. Получено дисперсионное уравнение, позволяющее рассчитать продольные волновые числа гибридных волн в каждом отрезке такой структуры, а также найдены выражения в замкнутом виде для коэффициентов связи в обобщенных матрицах рассеяния трех видов стыков. Найдена обобщенная матрица рассеяния всего рупора, что позволило получить амплитудное и фазовое распределение собственных волн на его апертуре при заданном возбуждении на входе. Применяя преобразование Фурье от найденного распределения электрического поля на апертуре рупора, решена внешняя задача электродинамики. Приведены результаты расчета дисперсионных характеристик и диаграмм направленности первых четырех гибридных волн коаксиального рупора с трехслойным диэлектрическим заполнением, которые подтверждают адекватность математической модели и ее пригодность для электродинамического анализа и оптимизации многодиапазонных коаксиальных облучателей зеркальных антенн
\end{abstract}

Ключевые слова: рупор с частичным диэлектрическим заполнением, гибридная волна, матричный метод согласования полей, собственная волна, метод преобразования Фурье

\section{1. ВВЕДЕНИЕ}

В последнее время, в связи с освоением новых диапазонов частот в спутниковых информационных системах и радиоастрономии, возникла потребность в создании высококачественных облучателей больших зеркальных антенн, работающих одновременно в нескольких разнесенных диапазонах частот, причем на ортогональных поляризациях при низких уровнях кроссполяризационного излучения в каждом из широких рабочих диапазонов частот. Среди высококачественных облучателей двухзеркальных антенн уже длительное время лидирующее положение занимают гофрированные рупоры $[1,2]$. Они работают на гибридных волнах и обеспечивают осесимметричную диаграмму направленности гауссовой формы с рекордно низким уровнем кроссполяризационного излучения в широкой полосе частот. Некоторой альтернативой гофрированным рупорам, хотя и не в полной мере, могут служить менее дорогостоящие гладкостенные рупоры с частичным диэлектрическим заполнением [3-5]. Они также работают на гибридных вол- 